\title{
The rivalry between online and direct selling - Is there a winner?
}

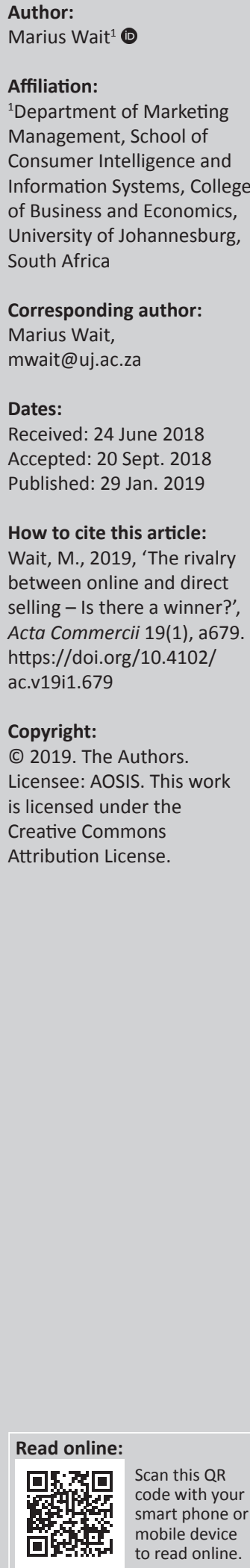

Orientation: With the advancement of technology and intense competition, many traditional direct selling companies have had to include an online sales channel to their offerings.

Research purpose: This study investigated the adoption of technology concerning online selling in the direct selling environment.

Motivation for the study: This study investigated whether there is a 'winner' between direct selling and online selling, as well as identifying the threats, impact and future of online selling in the direct selling environment.

Research design, approach and method: The study adopted a qualitative approach. A postcard-type, open-ended questionnaire was used to collect data from the directors of the direct selling companies. The collected data was analysed using inductive content analysis.

Main findings: The main results indicate that online selling is here to stay and there is no winner between these two forms of selling.

Practical/managerial implications: Managers should adopt a flexible approach to multichannel retailing as consumers dictate the consumption of sales channels in a multichannel sales arena.

Contribution/value-add: Although this paper contributes on three levels - namely, theoretical, methodological and practical - it is the practical contribution that adds the biggest value and there is no golden formula in the structure of this multichannel sales system.

\section{Introduction}

With the advancement of technology, as well as an intense competitive environment, many direct selling companies have had to complement their traditional direct selling channel with an online selling channel. The unique characteristics and functionality of direct selling differentiate it from other retail channels. This form of selling focuses on face-to-face interaction and relationshipbuilding. The online channel in the retailing or sales arena, which is considered impersonal, has become very dominant and can be considered a disruptive development (Verhoef, Kannan \& Inman 2015:174). This advent of online selling has dramatically changed the application of direct selling and the business model of direct selling companies. Although the inclusion of a new online channel may present several opportunities, the threats are also manifold (Duch-Brown et al. 2017:31; Pozzi 2013:569). The use of a two-channel process to sell products to consumers - a multichannel sales system - is on the increase (Lewis, Whysall \& Foster 2014). Karray and Sigué (2018) and Pu, Gong and Han (2017:1) believe that this multichannel system is not stagnant but rather that it is continuously changing and undergoing dramatic development.

While there is plentiful research on the use of technology in sales, very little tackles the influence of the adoption of technology in the direct selling environment (Ferrell, Gonzalez-Pardon \& Ferrell 2010:157). In response to this, an exploratory study was conducted amongst the member companies of South Africa's (SA) Direct Selling Association (DSA), and the research aim of this study was to explore and describe the perceptions of direct selling company executives on online selling in the direct selling environment. The areas of exploration were as follows:

- to determine the percentage of total sales made via online selling by direct selling companies

- to explore the threats experienced from the advancement of online sales technology

- to explore how companies have been impacted by the increase in online selling

- to explore the future of online selling in a direct selling company

- to explore the global trends of online selling in a direct selling company.

This paper contributes on three levels: theoretically, it adds to the limited body of knowledge on the adoption of online selling technology within a direct selling environment; methodologically, 
using a postcard-type, open-ended questionnaire to stimulate participation; and practically to provide guidelines obtained from the results that can add value to the companies involved.

The article has been structured such that the next section presents the theoretical framework guiding the study and this is followed by the methodology and presentation of findings. Thereafter the results are discussed and their theoretical and managerial implications presented. Finally conclusions are made and limitations as well as suggestions for future research are presented.

\section{Literature review}

The literature reviewed used many terms or concepts interchangeably, which may confuse readers. For example, some authors refer to offline sales as any method other than online sales; some authors refer to online sales as the e-channels; and some authors refer to the use of two retail channels simultaneously as dual channels, while others call the same concept 'multichannels' (Dinner, Van Heerde \& Neslin 2014; Ferrell et al. 2010; Karray \& Sigué 2018; Wang, Leng \& Liang 2018). For the purpose of this study, the terms 'direct selling', 'online selling' and 'multichannels' will used as explained in the following.

The key research issues that will be addressed in the literature review involve the following:

- South Africa's DSA - a snapshot of the current environment in which this study took place will be presented.

- Direct selling - in this section, the mechanics of direct selling will be investigated.

- Online selling - the advancement of technology will be explained.

- Multichannel retailing - the concept of using two sales channels simultaneously will be examined.

\section{South Africa's Direct Selling Association}

There are currently 63 DSAs globally, all of which are affiliated with the World Federation of Direct Selling Associations (WFDSA). South Africa has one of these DSAs (WFDSA 2016). According to the DSA of SA (2016a), it is 'a self-regulating association of direct selling companies that promotes and protects the interest of its members, distributors and consumers'. South Africa's DSA was founded in 1972 and represents its member companies, currently 31, ensuring that they adhere to the industry's code of conduct. This industry employs 1.33 million direct sellers (Du Toit 2017). Table 1 illustrates the monetary value of the direct selling industry in SA, Africa and globally as reflected by the 2015 to 2016 total sales.

In the 2016 financial year, global direct sales were at $\$ 182.6$ billion, showing a growth of close to $2 \%$ from the previous year, with SA also displaying healthy statistics. South Africa's DSA has shown just over an $18 \%$ increase in year-on-year sales from 2015 to 2016. Total industry sales accounted for
TABLE 1: Total size of the Direct Selling Association, in terms of the 2015 to 2016 total sales.

\begin{tabular}{lccc}
\hline Variable & 2015 (bn) & 2016 (bn) & $\begin{array}{c}\text { Growth percentage } \\
\text { year-on-year (\%) }\end{array}$ \\
\hline South Africa & R10 930 & R12 915 & 18.16 \\
Rest of Southern Africa & R1053 & R1066 & 1.23 \\
Rest of Africa & R2088 & R1880 & $(9.96)$ \\
Total Africa & R14 071 & R15 861 & 12.72 \\
Global & $\$ 179.2$ & $\$ 182.6$ & 1.9 \\
\hline
\end{tabular}

Source: Du Toit, E., 2017, DSA - Direct Selling Industry results and trends 2016 speech, DSA Annual Awards luncheon, 18 July 2017

Note: Data in brackets indicate a negative.

$R$, South African rand; $\$$, US dollar; bn, billion.

TABLE 2: Product mix of South Africa's Direct Selling Association.

\begin{tabular}{lc}
\hline Product group & Percentage of total sales (\%) \\
\hline Personal care & 46.1 \\
Household goods & 27.2 \\
Health and wellness & 19.9 \\
Financial products & 6.5 \\
Other & 0.3 \\
Total & $\mathbf{1 0 0 . 0}$
\end{tabular}

Source: Du Toit, E., 2017, DSA - Direct Selling Industry results and trends 2016 speech, DSA Annual Awards luncheon, 18 July 2017

TABLE 3: Percentage age breakdown of salespeople.

\begin{tabular}{lccc}
\hline Age & $\mathbf{2 0 1 5}$ & $\mathbf{2 0 1 6}$ & Percentage growth year-on-year (\%) \\
\hline$<35$ years & 23.7 & 28.22 & 4.52 \\
$36-44$ years & 25.6 & 29.28 & 3.68 \\
$45-54$ years & 27.8 & 22.56 & $(5.24)$ \\
$55-64$ years & 18.4 & 13.84 & $(4.56)$ \\
$>65$ years & 4.5 & 6.1 & 1.6 \\
\hline
\end{tabular}

Note: Data in brackets indicate a negative.

Source: Du Toit, E., 2017, DSA - Direct Selling Industry results and trends 2016 speech, DSA Annual Awards luncheon, 18 July 2017

approximately R13bn in SA in 2016. These figures represent a broad range of companies and their products (Table 2).

In 2016, the products that contributed the most to sales were personal care products, accounting for around 50\% of the total sales - this included body care and hair care products, as well as cosmetics. The salespeople of these products are of various ages (Table 3 ).

Although the majority of direct sellers in 2016 were aged 36-44 years, the best growth of new direct sellers entering the industry happened in the category of those aged 35 years and younger. It is interesting to note that the number of direct sellers aged between 45 and 64 years decreased significantly from 2015 to 2016, with those of pensionable age - that is, 65 years and older - having increased slightly. Close to $60 \%$ of direct sellers in 2016 were younger than 44 years.

\section{Direct selling}

Ferrell et al. (2010:157) state that direct selling has existed for decades and is a type of non-store retailing where all direct sellers are non-salaried, and the traditional notion of direct selling is of an industry that is face-to-face and peopleorientated where relationships are formed. There are many other definitions of direct selling (Ferrell et al. 2010; Kotler \& Armstrong 2016; Van Heerden \& Drotsky 2015). 
Kotler and Armstrong (2016:494) define direct selling as 'a personal presentation by the organization's sales force for the purpose of making sales and building relationships'. Van Heerden and Drotsky (2015:6) state that direct selling consists of a sequential process of 10 steps: prospecting, pre-approach, approach, presentation, trail close, uncovering objections, meet objections, trial close, close and follow-up (where the building of a relationship starts).

As this study was conducted within the context of DSA (2016a) in SA, its definition of direct selling will be used for this study, which is:

Direct Selling is a professional distribution channel that offers entrepreneurial and income generating opportunities. Rebates are earned through your personal sales to customers as well as from sales made by your own sales team.

The DSA (2016b) defines direct sellers, who they also refer to as independent business operators, as:

micro-entrepreneurs who market and sell products and services, typically outside of a fixed retail establishment, through one-toone selling, group product demonstrations/presentations (also referred to as Party Plan) or a combination and with online support. It's all about personal relationships.

It is important to mention that all the definitions reviewed have the similarity of face-to-face interaction and relationshipbuilding as segments of the mechanics of direct selling.

\section{Online selling}

In the current business environment, online shopping has become a part of individuals' lives because of its high efficiency and convenience. The number of online shoppers is also increasing year-on-year (Hong et al. 2017:30). According to Ferrell et al. (2014:157), sales technology that is used to facilitate online selling refers to 'firm-provided technologies that can facilitate or enable the performance of sales tasks'. They further state that the broad range of technologies used by salespeople include sales force automation, sales-based customer relationship management, media like online social network and mobile technologies, and companies' own websites. When adding online selling to an existing channel, such as direct selling, there are three issues that a company needs to consider: if the addition provides additional sales; if this additional channel will cause cannibalisation, wherein existing sales and consumers are merely diverted from one channel to the other; and if a new online selling channel will provide new customers (Hernant \& Rosengren 2017:306).

Online selling has unique features, such as substantially reducing search costs; granting easy access to product and price information; facilitating product comparisons; offering greater accessibility, convenience and time-saving; and it involves no travel, product carrying or restrictions on shopping hours. However, there are also many drawbacks as it does not permit physical examination (feel, touch, smell, sample and trail), it does not offer interpersonal communication or instant gratification and often involves extra shipping and handling costs (Chu et al. 2010:251). Furthermore, Chu et al. (2010:252) believe that the consumer exhibits different behaviour when shopping online or purchasing products through the direct seller. Therefore, it is very important for the company to understand how these different consumer types behave.

\section{Multichannel retailing}

The rate at which digital technology is expanding combined with the growth in the intensity of competition has compelled companies to introduce a multichannel sales system (Lapoule \& Colla 2015:248). This multichannel approach has increased since the late 1990s (Lewis et al. 2014:44). Karray and Sigué (2018) and Lewis et al. (2014:43) state that a company is considered to use multichannel retailing when it sells products to consumers through at least two different channels, like online and direct selling as in the case of the DSA companies. Karray and Sigué (2018) express that there are numerous benefits to multichannel retailing, such as access to new markets, increased customer satisfaction and loyalty, and the creation of strategic advantages. This sentiment is also shared by Hernant and Rosengren (2017:305), who add that insight gained across channels can increase the customer relationship through customisation. Lewis et al. (2014:44) opine that there are three key drivers that motivate the adoption of a multichannel system, namely the advancement of technology, the changing shoppers' behaviour and the benefits associated with a multichannel system. These authors also list three obstacles in the adoption of a multichannel system, which are the need to acquire new resources or change current resources, achieving channel integration and challenges in acquiring a multichannel system.

Dinner et al. (2014:527) argue that a multichannel system can create opportunities, but it is also an increasingly complex problem for companies that need different management principles.

In summary, direct selling and online selling are at opposite ends of the sales spectrum. Online selling has no human (buyer-seller) interaction and so no personal communication or interaction, an element that drives traditional direct selling. The advancement of technology and competition drives online selling, while the traditional mechanism of direct selling is all about the face-to-face interaction as well as relationship-building. The combination of these two channels into multichannel retailing has brought forth new management principles. It is this rivalry between online and direct selling that this study will explore further using the opinions of DSA directors - the methodology followed for this study is described next.

\section{Methodology Research instrument}

This study used a qualitative methodology, as the aspects under investigation were exploratory and interpretive in nature. The researcher also wanted to obtain meaning from 
the text and used inductive content analysis as the research instrument. Inductive content analysis is utilised in cases where there are no previous studies on the phenomenon under investigation, and the categories and coded texts are derived directly from the text (Vaismoradi, Turunen \& Bondas 2013:398). In this study, the text used for coding was the participants' feedback.

\section{Target group and sample decision}

A postcard-type questionnaire was sent to an independent person, who distributed and collected the results with the aim of assuring anonymity. The questionnaire was distributed to all member companies. All forms of identification, such as e-mail addresses, were removed from the questionnaire forms before the results were returned to the researcher. The questionnaire contained five short open-ended questions where participants were asked to provide as much detail as possible. The results of the study were based on information received from 13 of SA's DSA member companies, representing approximately $36 \%$ of total members. The responses were from a broad range of companies and products or services sold. The products and services ranged from cosmetics, personal care and homeware to health, wellness, financial and insurance. The responses represented executive opinions only, those of directors from both larger and smaller DSA member companies.

Fusch and Ness (2015) posit that the number of responses in qualitative research is determined by when data saturation is reached. Data saturation is achieved when there is enough information to replicate the study, when the ability to obtain new information has been reached and when further coding is no longer feasible. However, data saturation must fit the qualitative research design, which depends on the sample size of the population. Researchers should aim for rich and thick data - rich in terms of quality and thick as in quantity. Rich data is layered, intricate, detailed and nuanced. Data saturation is not about numbers but about the depth of the data. Because of the total number of responses in relation to the population $(36 \%)$, the broad range of companies, as well as the opportunity for participants to answer as extensively as possible, both rich and thick data was gathered from the questionnaire. Elo et al. (2014:8) state that the trustworthiness of content analysis depends on the availability of such rich, appropriate and well-saturated data - as was obtained in this study. Trustworthiness also depends on the manner in which the data is collected. In this study, all data was anonymised before it was sent on to the researcher.

\section{Research analysis}

This study used an explorative design, working through text with an inductively formulated category system, and it utilised the Mayring (2014:80) inductive content analysis procedural model (Figure 1).

Step 1 - Research questions. Formulate a clear research question, not just a topic or a title. The research question must fit an inductive logic, which means it must be explorative. The aim of this study was to explore and describe direct selling company executives' perceptions on online selling in the direct selling environment. The theoretical background must be described using literature and previous studies. This section of the study is covered in the literature review section. As this study is conducted within the context of the DSA and to provide depth to Step 1, the DSA's website was consulted.

Step 2 - Category definition and level of abstraction. The category definition, which has to be explicit, serves as a selection criterion to determine the relevant material from the texts. The level of abstraction defines how specific or general categories have to be formulated, which is central to inductive category formation. For the purpose of this study, the areas of exploration were operationalised into category definitions. These are as follows: to determine the percentage of total sales made via online selling; to explore the threats experienced from the advancement of online sales technology; to explore how companies have been impacted by the increase

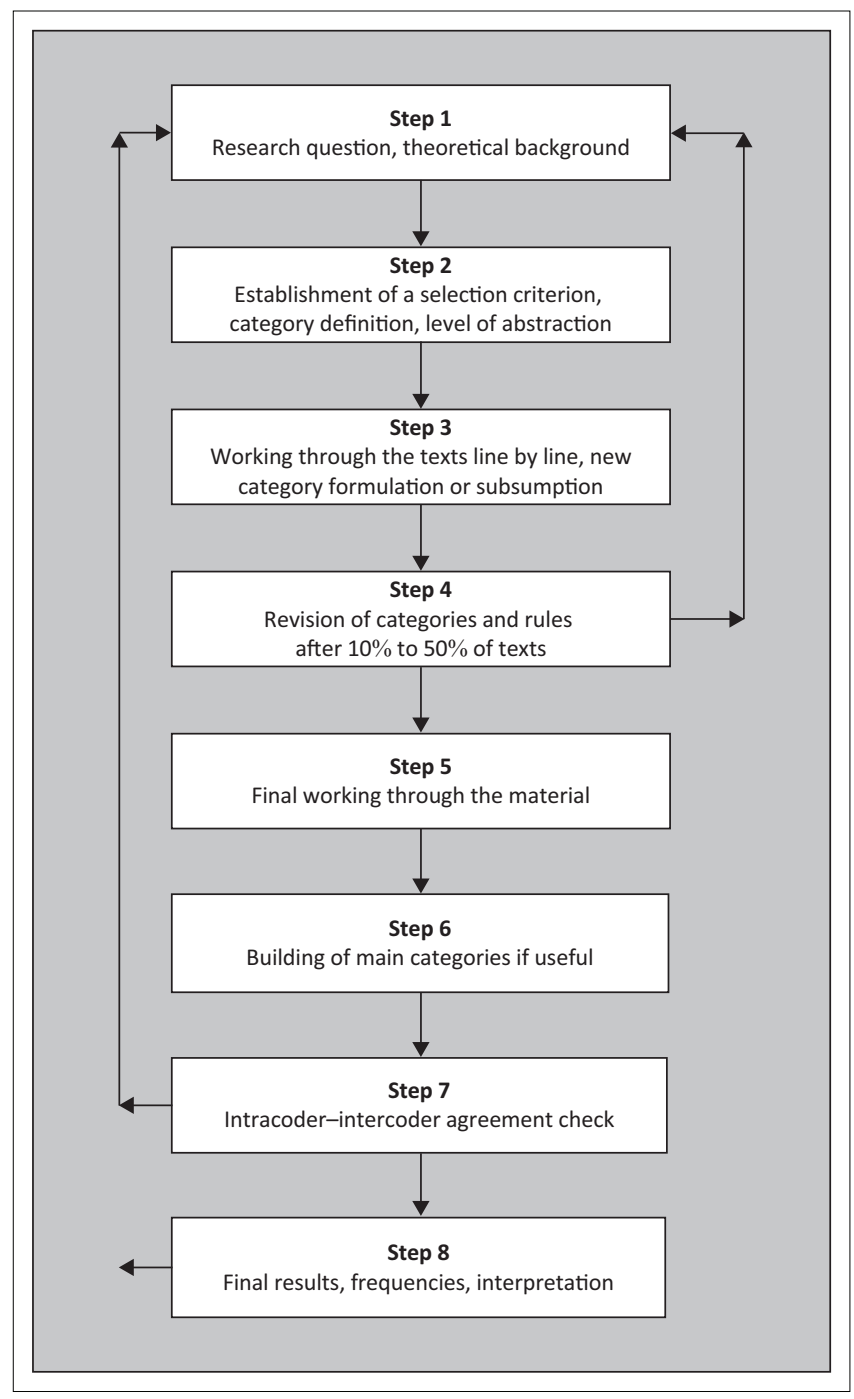

Source: Mayring, P., 2014, Qualitative content analysis: Theoretical foundation, basic procedures and software solution, p. 80, Social Science Open Access Repository, viewed 10 May 2018, from https://www.ssoar.info/ssoar/handle/document/39517

FIGURE 1: Steps of inductive category management. 
in online selling; to explore the future of online selling in a direct selling company; and to explore the global trends of online selling in a direct selling company. Step 2 is covered in the introduction, the literature review and the respondents' feedback. This feedback served as the unit of analysis.

Step 3 - Coding the text. Read the feedback material slowly from beginning to end. Check if there is material that relates to the category definition. Formulate a category near to the text at the level of abstraction. If the next passage fits the category definition, check if it can be subsumed to fit the first category or if a new category has to be formulated, and so on. Steps 3 to 7 were done on the feedback of the open-ended questions, each time improving on the previous step.

Step 4 - Revision. A revision in the sense of a pilot loop is necessary, when the category system seems to become stable. Check if the category system fits the research question. If it does not, a revision of the category definition is necessary. Check if the degree of generalisation is sufficient. If there are only a few categories, then the level of abstraction is too general. If there are many categories then the level of abstraction is too specific.

Step 5 - Final coding. The whole material - in this case, the respondents' feedback - has to be worked through with the same rules - that is, category definition and level of abstraction.

Step 6 -At the end of this process, you have a list of categories. Group them together and build the main categories, keeping in line with the research question.

Step 7 - Intra- or intercoder check. Start coding from the text from the beginning. Code text into categories.

Step 8 - Results. The results are at first the list of categories. If categories have to be found for several text passages - as in the case of this study, there were 13 manuscripts - a frequency analysis of the categories' occurrence could be useful. The categories and the frequencies have to be interpreted in the direction of the research aim. Step 8 revealed the results of this study and is presented in the following section.

\section{Ethical considerations}

South Africa's DSA did the research amongst its member companies to determine the effect of the advancement of technology on the role of the traditional sales person. The results of the 13 company participants were anonymised before they were given to the researcher. Permission was obtained from South Africa's DSA to conduct the study and the subsequent publication of the results obtained.

\section{Results and discussion}

The results were analysed from the answers provided in the open-ended questionnaire and were formulated to reflect the main categories that emerged. All the participants were enthusiastic in their responses and gave strong feedback. The 13 participants, with direct quotations, will be referred to as P1 to P13.

When company directors were asked to indicate approximately what percentage of total sales were made through online selling, the results were extremely thought-provoking. No category formation and coding could be done with this objective, as there were no similarities. From the 13 participants, 13 different responses were received and there was no agreed upon formula. The results varied from $100 \%$ online selling and $0 \%$ direct selling to $5 \%$ online selling and $95 \%$ direct selling. The vast majority of the companies followed a blended approach, with some online and some direct selling. Lewis et al. (2014) found similar results in a study where companies differed in their channel integration percentages. These results also tie in with those of Karray and Sigué (2018), who stipulate that the retailing sector and traditional marketing channel structures are in perpetual mutation, as many retailers adopt this multichannel system. The consumers' needs are also addressed in this result, and Chu et al. (2010:252-253) and Lewis et al. (2014:43) state that this dual mutation approach is also evident in consumers' buying behaviour, which is changing. Consumers' behaviour across different channels contrasts, and consumers use the two channels differently some may use the direct seller as a primary channel and the online as a supplementary channel, whereas others may follow a reverse pattern. Therefore, customers can choose which channels they use for various stages of the buyer behaviour process. This multichannel shopper is the new norm.

Concerning the threats that the DSA companies face from the advancement of technology, tradition was the major category raised. Tradition must be seen as twofold - generally, older or traditional salespeople being left behind with technological developments; and the traditional role of the direct seller as being a relationship-builder, both of which are now being diminished.

'We have seen that the advancement of technology, particularly in sales, has the potential of leaving behind what is considered the older generation of individuals that contribute large amounts of sales value to the business.' (P1)

'Increased online sales could potentially reduce the face-to-face interaction which direct selling is known and loved for.' (P6)

'[O]nline channels create disconnect between upline and downline, therefore undermining the referral sales or relationship strategy that is at the heart of multilevel-marketing.' (P12)

Another interesting and important category to note, which contradicts the previous category, is that a large portion of the participants stipulated that they had not experienced any threats so far.

'Currently we don't foresee any threats - in fact, we will embrace any development in the online space.' (P8)

This incongruity in the results is not strange, as corroborated by Herhausen et al. (2015:310), who state that adding another channel may be either a zero-sum game where advantages in one channel are offset by 
disadvantages in another channel or may even cause harm to companies. Thus, the addition of a new channel can present both opportunities and threats - it can enhance or destroy performance.

On exploring the impact of an increase in online selling on the companies, the results were overall ambiguous. This section will categorise positive and negative impacts separately. The vast majority felt no negative impact on the company: 'No negative impact' (P3). It would be incorrect to assume that these participants felt a positive impact in the absence of a negative impact. Only a few participants stated that they had felt a positive impact: 'our online channels are empowering our representatives or consultants by enabling them to run their businesses more efficiently' (P6). Ferrell et al. (2010:157) speak of uncertainty and state that the increase in online selling can be the change agent that reinvents the role of the direct seller. Online sales technology challenges the tradition in this industry. This result must be read in conjunction with the previous outcome dealing with threats.

When participants were asked to give their opinions on the future of online selling in a direct selling environment, nearly all of them stated that they believed online selling was here to stay. 'Direct selling companies will have to embrace online sales' (P5) and ' $w$ ] e see a promising future for online interaction with our representative or consultant' (P6). This result is in line with Lewis et al. (2014:47), who state that this new multichannel shopping concept should be accepted as it can leverage many benefits for the company, such as an increased number of customer contact points and reduced operating costs. Compared to the minority customer, the multichannel shopper is becoming mainstream. The multichannel system is being adopted by a larger number of retailers, not only in the direct selling sector but by brick-and-mortar retailers as well.

Regarding global trends for online selling in a direct selling company, the majority of the participants felt that global online growth would change the way direct sellers do their business.

\footnotetext{
'The pressure is on all direct selling companies to have a keen look at their processes and how to simplify them.' (P1)

'Globally, online sales is definitely affecting our direct selling companies and we need to be ready to get online, but never bypass the sales force if we want to be competitive in the market.' (P7)
}

This result ties in with the findings of Hübner, Holzapfel and Kuhn (2015:84), who state that the expansion of online offerings is significantly changing the retail structures. Companies need to create new supply chain and operational models that can cope with online requirements in a multichannel strategy (Lewis et al. 2014:43). Pu et al. (2017:1) express that online selling and direct selling should be integrated and not operate independently. The one channel can stimulate demand in another - for example, a consumer could be directed to 'experience' (touch, feel and smell) the product before an online purchase is done. The online platform can provide contact details of the nearest direct seller. This sentiment is shared by Baal (2014:1038), who states that all channels in a multichannel system should be coordinated. Proper channel integration should enrich customers' value proposition Herhausen et al. (2015:310).

In summary, all the participants felt that online selling and the advancement of technology was an 'exciting new must' for direct selling companies. The feedback reflects a general positive attitude towards the development of technology and companies are eager to try this out. However, throughout the texts during the coding phase, two issues emerged constantly: the traditional role of direct selling where relationships are formed is diminished; and the older generations, who in many cases are productive sellers, are left behind. Herhausen et al. (2015:310) state that adding a new channel can be performance-destroying as well as performanceenhancing. The biggest proportion of direct sellers were younger than 45 in the 2016 company survey, and this category showed the best growth in the number of new direct sellers. The older category of 65 years and older only represents less than $10 \%$ of direct sellers (Table 3).

Some of the results were ambiguous and sometimes contradictory. There are many uncertainties that the DSA companies have to be content with in this new online world. However, this perpetual mutation could be the correct formula (Chu et al. 2010; Karray \& Sigué 2018; Lewis et al. 2014).

\section{Limitations}

This study was conducted on a national level in SA. The feedback received accounts for $36 \%$ of the total population of direct selling companies affiliated with SA's DSA and represents various product categories. This study can be generalised to include all DSA companies in SA but should not be generalised on a global level.

\section{Managerial implications}

The current practices used to sell products to the final consumer need to be reworked non-stop. If managers want to stay up to date with the technologically changing world, a flexible multichannel sales system should be considered. In this multichannel sales system, managers should be flexible and not prescriptive, as the literature and results indicate that this phase is in 'perpetual mutation' and will consciously change. This will optimise the various consumer types' buying behaviours as well as staying abreast with the advancement of technology. Managers should integrate the two channels and not operate them as independent entities, as this will create value to the consumer. One channel should reflect the other and vice versa.

\section{Conclusion}

There is no winner in the rivalry between online and direct selling. Direct selling companies use a blended approach in the formulation of a multichannel system, consisting of online and direct selling. There is no golden formula and this system can create uncertainty for companies. Although the 
results are filtered through the lens of company directors, this conclusion must be seen from two perspectives: the direct selling company and the consumer. For the companies, the multichannel sales system should not be prescriptive as the consumer is the dictator in this environment and will direct the dominance of one channel over another channel. This dual approach will service the needs of the different consumer types. This flexible multichannel sales system can create opportunities but is also an increasingly complex problem for companies to manage.

The aim of this research article was to explore and describe direct selling company executives' perceptions of online selling in the direct selling environment, and it used five objectives to achieve this goal. By the magnitude of total sales made - close to R13bn in 2016 - and the 1.33 million direct sellers in operation, online selling has an enormous impact on SA's DSA.

The role of the salesperson in the age of technological advancement must be redefined, and the buyer-seller relationship in the online sales arena also needs a new definition. The definition of e-relationship is a vital component for the future of direct sellers with an online system. This loss of the relationship seems to be a strong argument to deliberate, as the definition of direct selling by the DSA specifically refers to the building of relationships.

Derived from both the literature and the results, the following could be starting points for future study opportunities:

- Do certain product groups, as reflected in Table 1, lend themselves better to online selling or to direct selling?

- Perform a comparative study of SA and the global environment to determine if the same results are obtained.

- In a study by Karray and Sigué (2018), several valid questions were raised that are also applicable to this study for future study opportunities:

- Does multichannel retailing actually grow sales?

- What is the contribution of an additional channel?

- Should channel prices be the same?

- In another study by Wang et al. (2018), another study opportunity was raised that is also applicable to this study, which is: Does an additional online channel increase sales or are sales cannibalised over a multichannel system?

- Lapoule and Colla (2015) raised another point that is also applicable to this study: 'To investigate the evolution of the role and position of the sales person'.

\section{Acknowledgments Competing interests}

The author declares that he has no financial or personal relationships that may have inappropriately influenced him in writing this article.

\section{References}

Baal, S., 2014, 'Should retailers harmonize marketing variables across their distribution channels? An investigation of cross channel effects in multi-channel retailing', Journal of Retailing and Consumer Service 21(6), 1038-1046. https://doi. org/10.1016/j.jretconser.2014.04.012

Chu, J., Arce-Urriza, M., Cebollada-Calvo, J. \& Chintagunta, P., 2010, 'An empirical analysis of shopping behavior across online and offline channels for grocery products: The moderating effect of household and product characteristics', Journal of Interactive Marketing 24, 251-268. https://doi.org/10.1016/j. intmar.2010.07.004

Dinner, I.M., Van Heerde, H.J. \& Neslin, S.A., 2014, 'Driving online and offline sales: The cross-channel effects of traditional, online display and paid search advertising', Journal of Marketing Research LI, 527-545. https://doi.org/10.1509/jmr.11.0466

DSA, 2016a, DSA purpose, viewed 01 May 2018, from http://www.dsasa.co.za/ modules_fe/layout2/default.asp

DSA, 2016b, defining direct sellers, viewed 01 May 2018 from http://www.dsasa. co.za/modules_fe/layout2/about_direct_selling_rm.asp\#direct_selling_explaine

Duch-Brown, N., Grzybowski, L., Romahn, A. \& Verboven, F., 2017, 'The impact of online sales on consumers and firms: Evidence from consumer electronics', International Journal of Industrial Organization 52, 30-62. https://doi. org/10.1016/j.ijindorg.2017.01.009

Du Toit, E., 2017, DSA - Direct Selling Industry results and trends 2016 speech, DSA Annual Awards luncheon, 18 July 2017.

Elo, S., Kääriäinen, M., Kanste, O., Pölkki, T., Utriainen, K. \& Kyngäs, H., 2014, 'Qualitative content analysis: A focus on trustworthiness', SAGE Open, 1-10. https://doi.org/10.1177/2158244014522633

Ferrell, L., Gonzalez-Padron, T.L. \& Ferrell, O.C., 2010, 'An assessment of the use of technology in the direct selling industry', Journal of Personal Selling and Sales Management 30(2), 157-165. https://doi.org/10.2753/PSS0885-3134300206

Fusch, P.I. \& Ness, L.R., 2015, 'Are we there yet? Data saturation in qualitative research', The Qualitative Report 20(9), 1408-1416.

Herhausen, D., Binder, J., Schoegel, M. \& Herrmann, A., 2015, 'Integrating bricks with clicks. Retailer-Level and Channel-Level outcomes of online-Offline channel integration', Journal of Retiling 91(2), 309-325. https://doi.org/10.1016/j. jretai.2014.12.009

Hernant, M. \& Rosengren, S., 2017, 'Now what? Evaluating the sales effects of introducing an online store', Journal of Retailing and Consumer Services 39, 305-313. https://doi.org/10.1016/j.jretconser.2017.08.010

Hong, H., Xu, D., Xu, D., Wang, G. \& Fan, W., 2017, 'An empirical study on the impact of online word-of-mouth sources on retail sales', Information Discovery and Delivery 45(1), 30-35. https://doi.org/10.1108/IDD-11-2016-0039

Hübner, A., Holzapfel, A. \& Kuhn, H., 2015, 'Operations management in multichannel retailing: An exploratory study', Operations Management Research 8(3-4), 84-100. https://doi.org/10.1007/s12063-015-0101-9

Karray, S. \& Sigué, S.P., 2018, 'Offline retailers expanding online to compete with manufacturers: Strategies and channel power', Industrial Marketing Management viewed 02 May 2018, from https://doi.org/10.1016/j.indmarman.2018.01.004

Kotler, P. \& Armstrong, G., 2016, Principles of marketing: Global and southern African perspectives, 2nd edn., Pearson, Sandton, South Africa.

Lapoule, P. \& Colla, E., 2015, 'The multi-channel impact on the sales force management', International Journal of Retail \& Distribution Management 44(3), 248-265. https://doi.org/10.1108/IJRDM-11-2014-0159

Lewis, J., Whysall, P. \& Foster, C., 2014, 'Divers and technology-related obstacles in moving to multichannel retailing', International Journal of Electronic Commerce 18(4), 43-68. https://doi.org/10.2753/JEC1086-4415180402

Mayring, P., 2014, Qualitative content analysis: Theoretical foundation, basic procedures and software solution, Social Science Open Access Repository, viewed 10 May 2018, from https://www.ssoar.info/ssoar/handle/document/39517

Pozzi, A., 2013, 'The effect of Internet distribution on brick-and-mortar sales', The RAND Journal of Economics 44(3), 569-583. https://doi.org/10.1111/17562171.12031

Pu, X., Gong, L. \& Han, X., 2017, 'Consumer free riding: Coordinating sales effort in a dual-channel supply chain', Electronic Commerce Research and Applications 22 1-12. https://doi.org/10.1016/j.elerap.2016.11.002

Vaismoradi, M., Turunen, H. \& Bondas, T., 2013, 'Content analysis and thematic analysis: Implications for conducting a qualitative descriptive study', Nursing and Health Sciences 15(3), 398-405. https://doi.org/10.1111/nhs.12048

Van Heerden, C.H. \& Drotsky, A., 2015, Personal selling, 3rd edn., Juta, Pretoria, South Africa.

Verhoef, P., Kannan, P. \& Inman, J., 2015, 'From multi-channel to Onmi-Channe Retailing introduction to the special issue on multi-channel retailing', Journal of Retailing 91(2), 174-181. https://doi.org/10.1016/j.jretai.2015.02.005

Wang, C., Leng, M. \& Liang, L., 2018, 'Choosing an online retail channel for a manufacturer: Direct sales or consignment?', International Journal of Production Economies 195, 338-358. https://doi.org/10.1016/j.ijpe.2017.11.001

WFDSA, 2016, Member DSAs, viewed 01 May 2018, from https://wfdsa.org/dsamembership-by-country/page/7/ 